Julien Picault*

\title{
Risk-Averse Managers, Labour Market Structures, Public Policies and Discrimination
}

DOI 10.1515/bejte-2015-0079

\begin{abstract}
This article presents a model to analyze the effects of first and secondmoment statistical discrimination on the labour market. Second-moment statistical discrimination occurs when risk-averse managers make decisions regarding wage and hiring based on productivity variances. We provide a framework exploring managers' discrimination based on differences in average productivity and in variance of productivity. Furthermore, since discrimination is composed of two types (wage and hiring discrimination), our model allows for the interdependence between hiring practices and wages. Using our model, we examine the effects of various anti-discrimination policies along with changes to the labour market structure. We show that managers' behaviour may be driven by anti-discrimination policies and labour market structures. A firm reduces hiring when required to implement anti-discrimination policies to address wage inequality. A firm applying policies to promote employment equity must stimulate minority participation. A change in labour market structure does not alter the efficiency of policies promoting employment equity, but it does alter the efficiency of policies aimed at reducing wage differences.
\end{abstract}

Keywords: second moment statistical discrimination, market structures, risk-aversion, public policies, first moment statistical discrimination

JEL Classification: J71, J78, J42, D20

\section{Introduction}

Statistical discrimination research has primarily focused on manager's decisions based upon the average characteristics of different groups when there is a lack of information about the characteristics of individuals. In markets other than the labour market, the analysis of statistical discrimination has been extended to consider decision making based on more than just the first moment of the

*Corresponding author: Julien Picault, Department of Economics, University of British Columbia - Okanagan, 3333 University Way, Kelowna, BC, Canada, V1V 1V7,

E-mail: julien.picault@ubc.ca 
characteristic. For instance, in her analysis of dealer discrimination in negotiations over used car sales Goldberg (1996) suggests that dealer bargaining strategies depend not only on the first moment of buyer reservation prices, but also on the second moment. This implies that first moments cannot be relied upon to fully explain existing patterns of discrimination.

A second moment of statistical discrimination refers to an additional layer of discrimination. Group characteristics not only differ in their average, but also in their variance. In the labour market, second-moment statistical discrimination occurs when risk-averse managers make decisions regarding wage and hiring based on productivity variances. Regardless of potential differences in their productivity, the disadvantaged group is considered to have a higher variance than the advantaged group. ${ }^{1}$ Including second-moment statistical discrimination requires more understanding about the distribution of the groups' productivity and no longer limits our understanding to direct measures of productivity. In our view, second-moment statistical discrimination and risk aversion may explain, at least in part, why discrimination persists despite the implementation of various public policies. If this is correct, public policies whose objective is to eliminate statistical discrimination may not be totally effective because they cannot be properly calibrated. For instance, Heckman (1998) and Neumark (2012) suggest that variances may limit the efficacy of the audit method for detecting discrimination. The bias induced by second-moment statistical discrimination, but missed by the policymaker, is not accounted for when calibrating and implementating current policies; therefore, they only provide an inadequate response to discrimination.

The objective of this paper is to propose a framework examining the discriminatory behaviour of employers in relation to differences in average productivity and in variances of workers' productivity. We analyse the hiring decisions of a manager using a mean-variance utility function. We express the variance of productivity (second-moment statistical discrimination) as the productivity distribution risk influencing the decisions of managers. Since discrimination is composed of two types (wage and hiring discrimination), our model allows for the interdependence between hiring practices and wage allocation.

This model can be used to examine the effects of various anti-discrimination policies and various labour market structures. It shows that firms' behaviour can

1 An example of second moment statistical discrimination can be found in Wozniak (2015). She demonstrated that managers employ more white women than black men when not allowed to conduct drug tests, and that employment of black men is more common where drug testing is allowed. In this case, black men could be seen as holding a higher variance while white women would have the lower variance. An anonymous referee suggested this example. 
be driven by anti-discriminatory policies and labour market structures. A firm reduces hiring when required to implement anti-discrimination policies to address wage inequality. A firm applying policies to promote employment equity must stimulate minority participation. A change in labour market structure does not alter the efficiency of policies promoting employment equity, but it does alter the efficiency of policies aimed at reducing wage differences. Specifically, we analyze two policies targeting employment discrimination and two targeting wage discrimination. For each market structure, we tested the effects of typical policies (quota and equal pay) against our proposed alternatives (minimum wage and disadvantaged employment subsidies). We adduce that our suggested policies are more efficient in reducing both first and second-moment statistical discrimination. Also, policies promoting employment equity could provide more effective results. The proposed disadvantaged employment subsidy is incentiveoriented while typical anti-discrimination policies are essentially constraining for a firm. It allows a firm to become part of the solution instead of being an object of " attack" and therefore, acts more as a carrot than a stick.

We also analyse various labour market structures to verify the effect of competition on discrimination and the impact when policies are implemented in various labour market structures. The impact of competition on discrimination represents a classic limitation of the standard discrimination frameworks. The literature indicates that discrimination should disappear in a competition context. Lang (1986) states: "neither the Becker-Arrow tastes model nor the Arrow-Phelps statistical discrimination model provides an adequate explanation of the persistence of discrimination". The model demonstrates that the more competitive the market is, the less discriminatory phenomena occur, even if competition is not potent enough to make them disappear. With this in mind, governments should take actions to foster competition in the labour market in addition to implementing anti-discrimination policies.

This paper is organized as follows. First, we develop the baseline model. Then we test the effects of labour market structures and public policies on wages and hiring.

\section{Literature}

Literature on the labour market is reluctant to consider risk-aversion as standards frameworks consider firms to be risk neutral. There is a presumption that managers can have risk neutral behaviours on most markets, because they can fully hedge risks on the financial markets. However, it is unrealistic to expect 
that risks generated through the hiring process can be fully hedged within the financial markets. Another common presumption of this view is that the law of large numbers cancels the effect of risk-aversion. According to the US census bureau, in 2008, 89.2\% of the firms employing at least one employee have no more than 19 employees and according to the OECD, in 2007, firms with between one and nine employees account for over $99 \%$ of all firms in the European Union and represent more than $80 \%$ of all firms in most OECD countries. This data illustrates the inappropriateness of refering to the law of large numbers as this law does not apply to most firms. Gathering more statistical information about potential employees can help to eliminate risk. In experimental work, Dickinson and Oaxaca (2009) examined various ways of measuring risk to reveal the existence of second-moment statistical discrimination in the labour market. They concluded that statistical discrimination is under-estimated if risk-aversion is not included in the model. The relevance of studying second-moment statistical discrimination comes not only from the possible measurement errors but also because it strengthens discriminatory outcomes. According to Klumpp and $\mathrm{Su}$ (2013), second-moment statistical discrimination offers a possible explanation to the "glass ceiling" for women.

In most statistical discrimination models, such as Bjerk (2008), Coate and Loury (1993), Klumpp and Su (2013) and Moro and Norman (2004), labour is supplied inelastically to firms providing the highest compensation. While this is one correct approach to model labour supply, it is not the only correct one. Our model illustrates another type of labour supply schedule. Labour supply is modeled with an upward slopping supply curve; therefore, this paper also illustrates the impact of an upward sloping labour supply curve.

Models, such as Bjerk (2008) and Klumpp and Su (2013), generally consider that the variance of skill signals impacts hiring and wages. Our model suggests a different approach using the variance of worker productivity instead of skill signals. A rationale to use productivity is that consistency in the product quality, consistency of practices, etc. are usually of paramount concern for many employers. Inconsistencies in production often have a cost to employers, especially for those involved in more standardized production. Sallie Krawcheck, the former president of the Global Wealth \& Investment Management division of Bank of America said to BBC in November 2013: “ what I saw a thousand times during the downturn was, 'we'd like to give her that opportunity, but we need to go with the sure thing - we can't afford diversity right now'."2 Her words illustrate the fact that in her case, signals were effectively received by employers but the perceived uncertainty on her productivity, due to her gender, justified not hiring her.

2 http://www.bbc.com/news/business-24525479 
In economics, the theoretical analysis of discriminatory phenomena started with Becker (1957) and Arrow (1972). They developed the first models which showed taste-based discrimination can be the cause of wage and employment discrimination. Welch (1976) provided a theoretical analysis of quotas and demonstrated that quotas redistribute income from advantaged to disadvantaged workers. A major criticism of this approach is that the exogenous preference for the advantaged group is not justified by clearly-expressed reasoning.

Phelps (1972) and Arrow (1972,) initiated the idea of "statistical discrimination." Statistical discrimination argues that employers have an information deficit about job candidates. The cost of having a comprehensive, "perfect" assessment of candidates is prohibitive. Employers base their hiring decision on all readily available information about candidates including visible sociocultural characteristics. Discrimination may arise from employers' unequal statistical knowledge of various socio-cultural groups.

In general, wage and hiring discrimination are usually studied independently in a standard statistical discrimination framework. However, they are strongly inter-related and our aim was to model them together in order to assess all the impacts resulting from their interdependence. Aigner and Cain (1977) and Lundberg and Startz (1983) are examples of statistical discrimination studies which focus primarily on wage discrimination. Aigner and Cain (1977) were the first to introduce the notion of risk aversion in the hiring process; differences in the average wage equal differences in productivity. According to Lundberg and Startz (1983), discrimination arises from differences in employers' assessment of the abilities of different groups. Bjerk (2008) shows that differences in precision of skill signals for skilled workers prior to entering the labour market is one rationale for the observed differences in promotion between the different groups. Studies by Cornell and Welch (1996) and Morgan and Vàrdy (2009) are examples of statistical discrimination analyses which focus primarily on hiring discrimination. Cornell and Welch (1996) showed that the hiring decision strongly favours the advantaged group because of difficulties in evaluating candidates. In their analysis of public policies, they suggest that a policy of equal pay would go against the representativeness of minorities. For their part, Morgan and Vàrdy (2009) have developed a job search model of statistical discrimination. They show that disadvantaged workers are under-represented and are fired more frequently than their non-disadvantaged peers.

In contrast to research on the sources of discrimination, very few theorybased studies have analyzed the effects of anti-discrimination public policies on employers' behaviours. The most recognized contribution in this regard is that of Coate and Loury (1993), who show that affirmative action may discourage disadvantaged workers from acquiring human capital. Lundberg and Startz 
(1983), Lundberg (1991) and Cornell and Welch (1996) provide policy prescriptions but not thorough analyses of various public policies in action. However, there is a wide body of empirical research on the subject such as Leonard (1984), Smith and Welch (1984) and Leonard (1990), showing that anti-discrimination laws have beneficial effects on the hiring and wages of women and minorities. ${ }^{3}$ Holzer and Neumark $(1999,2000 b)$ found that employers under affirmative action regimes use more intensive screening of job candidates, which increase chances of uncovering other information about disadvantaged workers and that they were more likely to have formal monitoring for evaluating their employees.

To be clear about the positioning of our paper in the literature, it provides a thorough theoretical analysis of public policies in a flexible mean-variance context where the manager of the firm is risk-averse.

\section{Baseline Model}

The theoretical challenge of the baseline model is to explain hiring and wage discrimination as an equilibrium. To do so, we develop a simple and flexible model which includes first and second-moment statistical discrimination. We then enter various public policies and labour market structures into the model. The main advantage of this model is that it is flexible enough to compare a variety of public policies and market structures with greater accuracy. The main drawback is that we have to use a reduced form of structural functions describing the labour market to be able to make the comparison, namely an affine labour supply and an additive utility function. However, we present a more general model in the appendix which has the same properties as the baseline model but is too complex mathematically to include public policies. We specifically chose reduced form functions to keep a modicum of simplicity; other functions can be used as long as they comply with the constraints of the model.

\subsection{Workers}

There are two groups $j$ of workers in the economy, $j \in(1 ; 2)$. Group 1 is comprised of advantaged workers (white, male, etc.) and Group 2 of disadvantaged workers (black, female, etc.). In the remainder of this paper, we describe Group 1 as

3 See Holzer and Neumark (2000a) for a complete review of theoretical and empirical studies on the effects of anti-discrimination laws. 
advantaged and Group 2 as disadvantaged. Each group is the same size in the model; however, size does not impact the analysis. Suppose both groups of workers have the same inverse labour supply curve: ${ }^{4}$

$$
w_{j}=e n_{j}+f
$$

where $w_{j}$ is the wage of a worker from group $j, n_{j}$ the hiring of workers from group $j$ and $e$ and $f$ the parameters of the affine labour supply curve. $f$ represents the reservation wage. Each worker $i$ from group $j$ produces $y_{j i}$ with a mean $\bar{y}_{j}$ and variance $\sigma_{j}^{2}$. The variance $\sigma_{j}^{2}$ can be interpreted as the manager's uncertainty with regards to the exact value of the worker's productivity and result of a productivity shock, that is independent and identically distributed (iid) across all workers.

\subsection{Firms}

The market for goods and services is assumed to be perfectly competitive. The price of goods is determined by the market and normalized to 1 , without losing generality. The profit of a firm is:

$$
\pi=\sum_{j=1}^{2} \sum_{i=1}^{n_{j}} y_{j i}-n_{j} w_{j} .
$$

Managers of the firm are risk-averse and maximize a mean-variance profit function: $\pi_{M V}$. In the monopsony and the oligopsony cases, managers are taking into account the labour supply when making hiring and wage decisions. Although managers cannot assess the worker's true productivity level, they hold some prior beliefs. We surmise that managers have incomplete and possibly biased information on the mean and/or the variance of productivity. $\bar{y}_{j}$ and $\sigma_{j}^{2}$ are determined via the manager's available information and personal beliefs, including group status (disadvantaged vs. advantaged). The manager's cultural and statistical knowledge as well as possible stereotypes can play a role. We assume that the manager's uncertainty about individual workers' productivity is group-oriented since $s /$ he has a different set of information for the different groups $\left(\sigma_{2}>\sigma_{1}>1\right)$. The manager does not differenciate between groups based on

\footnotetext{
4 With this assumption, we can control for effects that do not result from labour supply differentials. We assume there is no difference between the groups so we can correctly assess the effects of public policies and market structures on discrimination. This assumption can be removed with no effect on the results of the tests.
} 
anything other than his beliefs on the mean and/or the variance of productivity. ${ }^{5}$ Considering all characteristics, a manager chooses the number of employees to hire $\left(n_{1}, n_{2}\right)$ and the wages $\mathrm{s} /$ he is willing to pay $\left(w_{1}, w_{2}\right)$ in order to maximize:

$$
\pi_{M V}=E[\pi]-\alpha \operatorname{VAR}[\pi] .
$$

The profit function can be reformatted as follows: ${ }^{6}$

$$
\pi_{M V}=\sum_{j=1}^{2}\left[n_{j}\left(\bar{y}_{j}-w_{j}\right)-\alpha n_{j}^{2} \sigma_{J}^{2}\right] .
$$

\section{Labour Market Structure}

Labour markets have been modeled in the literature using different market structures from perfect competition to monopsony. To reflect the large spectrum of market powers existing in labour markets, we develop a baseline model using three labour market structures: monopsony, oligopsony and competition. Also, this section examines how discrimination changes with competition. ${ }^{7}$

\subsection{Monopsony}

As a monopsonist, the firm takes advantage of its dominant position in the labour market; therefore, it includes the labour supply in its hiring and wage decisions. With this additional information, the optimal hiring behaviour of the firm is determined by the following maximization program:

$$
\max _{n_{j}} \sum_{j=1}^{2}\left[n_{j}\left(\bar{y}_{j}-f-e n_{j}\right)-\alpha n_{j}^{2} \sigma_{J}^{2}\right] .
$$

5 The model is designed to consider both first- and second-moment statistical discrimination but can easily be adapted for first-moment statistical discrimination only $\left(\sigma_{2}=\sigma_{1}\right)$ and for second-moment statistical discrimination only $\left(\bar{y}_{1}=\bar{y}_{2}\right)$.

6 We assume that $y_{1}$ and $y_{2}$ are uncorrelated. It's very important to understand correctly the meaning of variances $\sigma_{1}^{2}$ and $\sigma_{2}^{2}$ in this model to appreciate the weakness of this assumption. $\sigma_{1}^{2}$ and $\sigma_{2}^{2}$ are firms' "specific" evaluation of risk induced by observable difference among groups (race, gender, etc...). The manager makes no other distinction among groups. Consequently, he/ she does not consider possible statistical consequences implied by inter-group relations since in his/her mind they do not exist. In fact, if $y_{1}$ and $y_{2}$ are correlated the model does not significantly change. See the appendix for the model which includes correlations.

7 For example: A change in market competition could result from the creation of productivity hubs to group firms of the same industry in the same geographic location (Silicon Valley, etc...). 
Optimal hiring decisions are: ${ }^{8}$

$$
n_{j}^{\star}=\frac{\bar{y}_{j}-f}{2\left(e+\alpha \sigma_{j}^{2}\right)},
$$

Wages associated with these hiring decisions are:

$$
w_{j}^{*}=e \frac{\bar{y}_{j}-f}{2\left(e+\alpha \sigma_{j}^{2}\right)}+f .
$$

Contrary to many findings of gender and race discrimination studies, diversity in the workplace still exists even if employment and wage differentials occur. The firm hires workers of both groups and there is no case where a group is not used. ${ }^{9}$ This stems from the monopsony feature of the model but part of the effect is also due to diversification following the manager's risk aversion. ${ }^{10}$ However, disadvantaged workers experience hiring and wage deficits in comparison to advantaged workers. These deficits are directly due to the manager's assessment of means $\bar{y}_{j}$, variances in productivity $\sigma_{j}^{2}$ and risk-aversion $\alpha$. This result shows that our model conforms to reality as it is consistent with observed evidence that disadvantaged workers are both less paid and less employed by the firm. The addition of the manager's risk-aversion and variances in productivity contribute to this rational explanation. If attention is restricted to first-moment statistical discrimination instead of considering both the first and the second-moment statistical discrimination, both wages and employment differentials would be understated.

\subsection{Oligopsony}

There are $K>1$ symmetrical firms competing in the labour market. We address the oligopsony problem by using a reverse Cournot competition with symmetrical firms; the goods and services market stays perfectly competitive. The inverse labour supply in the oligopsony market structure becomes:

$$
w_{k j}=e\left(\sum_{k=1}^{K} n_{k j}\right)+f .
$$

\footnotetext{
8 See the appendix for more detailed calculations.

$9 n_{j}$ is always strictly positive with finite parameters.

10 To support the existence of the diversification effect, this section on market structures shows that diversity in the workplace is independent of the labour market structure.
} 
The optimal hiring behaviour is determined by the following maximization program:

$$
\max _{n_{i j}, w_{i j}} \sum_{j=1}^{2} n_{i j}\left[\bar{y}_{j}-f-e\left(n_{i j}+\sum_{k \neq i} n_{k j}\right)-\alpha n_{i j} \sigma_{j}^{2}\right] .
$$

Optimal hiring decisions are: ${ }^{11}$

$$
n_{i j}^{o}=\frac{\bar{y}_{j}-f}{e(K+1)+2 \alpha \sigma_{j}^{2}} .
$$

Wages associated with these hiring decisions are:

$$
w_{j}^{o}=e K \frac{\bar{y}_{j}-f}{e(K+1)+2 \alpha \sigma_{j}^{2}}+f .
$$

No major differences on discrimination are observed with an oligopsony market structure. The few changes observed were on hiring and wage levels. Indeed, discrimination against the disadvantaged group still occurs.

Effect on Wages: The oligopsony market structure increases the wage for both groups in comparison with monopsony; moreover, wage differentials decrease.

Effects on Hiring: The oligopsony market structure increases hiring in comparison with the monopsony, and hiring discrimination decreases.

\subsection{Competitive Labour Market}

There are $L>K$ symmetrical firms in a competitive labour market. Inverse labour supply for the competitive environment can be reformulated as:

$$
w_{k j}=e\left(\sum_{k=1}^{L} n_{k j}\right)+f .
$$

The optimal hiring behaviour is determined by the following maximization program. $w_{1}$ and $w_{2}$ are set by the competitive labour market. Here, the firm is simply recruiting given the competitive wage.

11 See the appendix for more detailed calculations. 


$$
\max _{n_{i j}} \sum_{j=1}^{2}\left[n_{i j}\left(\bar{y}_{j}-w_{j}\right)-\alpha n_{i j}^{2} \sigma_{j}^{2}\right] .
$$

Optimal hiring decisions are: ${ }^{12}$

$$
n_{i j}^{c}=\frac{\bar{y}_{j}-f}{e L+2 \alpha \sigma_{j}^{2}} .
$$

Wages associated with these hiring decisions are:

$$
w_{j}^{c}=\frac{e L}{e L+2 \alpha \sigma_{j}^{2}}\left(\bar{y}_{j}-f\right)+f .
$$

The effects on wages and hiring in the competitive market were the same as those in the oligopsony market structure.

\subsection{Impacts of Labour Market Structures}

Changing a monopsony market structure to an oligopsony or a competitive market structure decreases the market power of the firm because competition among firms increases in the labour market. When competition increases, workers have more market power. So workers are able to earn more for the same work and benefit from greater demand for their services because the labour market has expended. In addition to reducing discrimination, the emergence of workers' market power leads to improved employment conditions, higher wages and more hiring.

To verify the reduction of discrimination in an oligopsony structure, we compare the following ratios: $\frac{K n_{i 2}^{o}-K n_{i 1}^{o}}{K n_{i 2}^{o}}=1-\frac{\bar{y}_{1}-f}{\bar{y}_{2}-f} \frac{e(K+1)+2 \alpha \sigma_{2}^{2}}{e(K+1)+2 \alpha \sigma_{1}^{2}}$ and $\frac{n_{2}^{*}-n_{1}^{*}}{n_{2}^{*}}=1-\frac{\bar{y}_{1}-f}{\bar{y}_{2}-f} \frac{e+\alpha \sigma_{2}^{2}}{e+\alpha \sigma_{1}^{2}}$ which are hiring gap proportions in oligopsony and monopsony. ${ }^{13}$ This comparison is valid for both wages and hiring since the equilibrium values are positively correlated. We can conclude that:

$$
\frac{n_{2}^{\star}-n_{i 1}^{\star}}{n_{2}^{\star}}>\frac{K n_{i 2}^{o}-K n_{i 1}^{o}}{K n_{i 2}^{o}} .
$$

Therefore, wage discrimination and hiring discrimination decrease in both oligopsony and competitive market structures compared to the monopsony

12 See the appendix for more detailed calculations.

13 We can similarly prove that a competitive market structure also reduces discrimination. 
market structure. Oligopsony and competitive market structures not only have a positive impact on the disadvantaged group but also on the advantaged group. If we compare the oligopsony with the competitive market structure, it is easy to demonstrate that anti-discrimination effects are greater with the competitive structure. The more competitive the labour market, the more wages and hiring increase, irrespective of the workers' group. The more competitive the labour market, the less discrimination occurs. Public policies which foster competition can therefore combat discrimination even if competition is not strong enough to entirely eliminate it. Nevertheless, wage discrimination and hiring discrimination persist whatever the market structure.

\section{Public Policies}

In this section, the baseline model is refined to include four different policies: equal pay, minimum wage, quota, and disadvantaged employment subsidy. We examine the effects of these policies on first and second-moment statistical discrimination to understand their effectiveness. Following Bhaskar, Manning, and To (2002) studies of labour market structures, we chose to feature the oligopsony case because it is considered to be a more plausible market structure. It gives limited market power to both sides of the market. We also developed the monopolistic and competitive models and we discuss for each policy the potential effects of market structures. Detailed calculations for the monopsony and the competition models are included in the appendix.

\subsection{Public Policies Addressing Wage Discrimination}

\subsubsection{Equal Pay Policy}

Equal pay policy is used by governments of most industrialized countries to decrease wage discrimination in labour markets. Conventional wisdom argues that an equal pay policy would bring the wages of the disadvantaged group into alignment with the advantaged group; however, nothing proves that the wages would converge at the higher level. In order to take account the equal pay policy, we add the constraint $w=w_{1}=w_{2}$ to the baseline maximization problem. This yields the following maximization program: 


$$
\begin{aligned}
& \max _{n_{i j}, w_{i j}} \sum_{j=1}^{2} n_{i j}\left(\bar{y}_{j}-w\right)-\alpha \sum_{j=1}^{2} n_{i j}^{2} \sigma_{j}^{2} \\
& \text { s.t. }\left\{\begin{array}{c}
w=w_{k 1}=w_{k 2} \\
w_{k j}=e\left(\sum_{k=1}^{K} n_{k j}\right)+f
\end{array}\right\}
\end{aligned}
$$

We restate the problem by introducing constraints in the objective function. The optimal hiring behaviour of the firm can then be determined by:

$$
\max _{n_{i 1}, n_{i 2}} \sum_{j=1}^{2} n_{i j}\left[\bar{y}_{j}-f-\frac{e}{2}\left(n_{i j}+\sum_{k \neq i} n_{k j}\right)\right]-\alpha \sum_{j=1}^{2} n_{i j}^{2} \sigma_{j}^{2}
$$

Optimal hiring decisions are: ${ }^{14}$

$$
\begin{gathered}
n_{i 1}^{\prime}=\frac{\bar{y}_{1} \sigma_{2}^{2}+\bar{y}_{2} \sigma_{1}^{2}-f \sum_{j=1}^{2} \sigma_{j}^{2}}{4 \alpha \prod_{j=1}^{2} \sigma_{j}^{2}+e(K+1) \sum_{j=1}^{2} \sigma_{j}^{2}} \\
n_{i 2}^{\prime}=\frac{2 \sigma_{1}^{2}\left(\bar{y}_{2}-f\right)}{4 \alpha \prod_{j=1}^{2} \sigma_{j}^{2}+e(K+1) \sum_{j=1}^{2} \sigma_{j}^{2}}-\frac{e(K+1)\left(\bar{y}_{1}-\bar{y}_{2}\right)}{2 \alpha\left[4 \alpha \prod_{j=1}^{2} \sigma_{j}^{2}+e(K+1) \sum_{j=1}^{2} \sigma_{j}^{2}\right]}
\end{gathered}
$$

The common wage is therefore: ${ }^{15}$

$$
w^{\prime}=e K \frac{\bar{y}_{1} \sigma_{2}^{2}+\bar{y}_{2} \sigma_{1}^{2}-f \sum_{j=1}^{2} \sigma_{j}^{2}}{4 \alpha \prod_{j=1}^{2} \sigma_{j}^{2}+e(K+1) \sum_{j=1}^{2} \sigma_{j}^{2}}+f
$$

Wage effects: Implementation of an equal pay policy does not equalize wages to the former level of the advantaged wage. Rather, it causes a convergence to an intermediate value located between wages of each group in the baseline model: $w_{2}^{\star} \leq w^{\prime} \leq w_{1}^{\star}$. We should emphasize that both groups are affected by the implementation of the equal pay policy, as advantaged workers are also affected by a decrease in their wage level.

14 See the appendix for more detailed calculations.

15 The value of the wage could differ depending on the wage-setting mechanism. In this paper, workers behaviours are not modeled. We assume that workers are offered a stated wage without negotiation and choose to accept or to decline the job based on the stated wage. However, the fact that the wage under the equal pay is different than the wage of the advantaged workers before the intervention is independent of the wage-setting mechanism as long as the intervention does not impose the wage to equal this value. 
Hiring effects: Even if an equal pay policy targets wages, this is not the only thing affected by the policy. The policy also lowers employment numbers for the two groups: $n_{j} \leq n_{j}^{\star}, \nabla j$.

Implementation of the equal pay policy does not fix the value of the wage the firm has to pay. The only constraint for a firm in implementing wage equality is to give an equal wage to all workers irrespective of their group. There is no obligation for the firm to keep wages at the advantaged wage level prior to the implementation of the policy. The optimal situation for the firm is to set wages for both groups at an intermediate level. When a policymaker chooses to implement an equal pay policy, it forces the price of labour to change, thereby completely deviating from the initial market equilibrium. However, from the firm's point of view, labour demands remain the same. The decision of the policymaker does not directly affect labour demands; therefore, the effects on the two groups of workers are as follows:

- Disadvantaged workers: On one hand, the willingness of the firm to hire disadvantaged workers decreases because the price of their labour has risen. On the other hand, this increase causes more participation of disadvantaged workers in the labour market. These two simultaneous effects create unemployment amongst disadvantaged workers.

- Advantaged workers: On one hand, the willingness of the firm to hire advantaged workers increases because of the decrease in the price of their labour. On the other hand, this decrease causes lower participation of advantaged workers in the labour market. These two simultaneous effects cause a shortage of advantaged workers.

The labour market becomes unbalanced because of the implementation of an equal pay policy. Unemployment among disadvantaged workers and a shortage of advantaged workers results in decreased employment for both groups. This causes a reduction in the total production of the firm.

First and second-moment statistical discrimination: The labour demand for advantaged and disadvantaged workers is affected by productivity differences perceived by the manager. In fact, the manager's labour demand for disadvantaged workers includes a factor that is negatively proportional to the perceived disadvantage $\left(\bar{y}_{2}-\bar{y}_{1}\right){ }^{16}$ The manager's labour demand for advantaged workers

16 Size of the reduction in labour demand for disadvantaged workers due to the perceived disadvantage: $\frac{e(K+1)\left(\bar{y}_{1}-\bar{y}_{2}\right)}{2 \alpha\left[4 \alpha \prod_{j=1}^{2} \sigma_{j}^{2}+e(K+1) \sum_{j=1}^{2} \sigma_{j}^{2}\right]}$. It also corresponds to the increase in labour demand for advantaged workers due to the perceived advantage. 
includes the same factor that is proportional to the perceived advantage $\left(\bar{y}_{1}-\bar{y}_{2}\right)$. The equal pay exacerbates first-moment statistical discrimination effects on employment. Second-moment statistical discrimination $\left(\sigma_{1} \neq \sigma_{2}\right)$ reinforces the effects of the first-moment statistical discrimination and creates additional differences, accentuating the employment gap and reducing wages of both groups of workers. The implementation of an equal pay policy worsens the effects of both first and second-moment discrimination on employment.

Labour market structure effects: Increased competition has a similar effect to that observed in the baseline model. Competition and equal pay do not generate specific synergies or interference with regards to combating first and secondmoment statistical discrimination.

\subsubsection{Minimum Wage}

For many years, and particularly since the World March of Women in 1998, women have demanded the creation and strengthening of the minimum wage to end discrimination against them. However, Cahuc and Laroque (2014) challenge the pertinence of the minimum wage, even in a monopolistic labour market. They deduced that minimum wage is of no use in the presence of an optimal tax schedule. We believe that the pertinence of using minimum wage could come from its capacity to reduce first and second-moment statistical discrimination in an imperfectly competitive labour market structure.

In this section, we challenge the relevance of an equal pay policy by studying minimum wage as a potential better means for reducing wage discrimination. The aim is to prevent the negative effects of equal pay on advantaged workers. Our intuition is that the effects of equal pay policy on disadvantaged workers could be reproduced without unwanted effects on advantaged workers. We set the minimum wage between disadvantaged and advantaged wages in the baseline model. ${ }^{17}$ Let $\underline{w}$ be the minimum wage. The maximization problem becomes:

17 Setting other levels of minimum wage would be trivial and not have better results in terms of wages and hiring. 


$$
\begin{gathered}
\max _{n_{i j}} \sum_{j=1}^{2}\left[n_{i j}\left(\bar{y}_{j}-w_{j}\right)-\alpha n_{i j}^{2} \sigma_{j}^{2}\right] . \\
\text { s.t.: }\left\{\begin{array}{l}
w_{j}=\max \left(\underline{w} ; w_{j}^{\star}\right) \\
w_{j}=e\left(\sum_{k=1}^{K} n_{k j}\right)+f
\end{array}\right\}
\end{gathered}
$$

Optimal hiring decisions are: ${ }^{18}$

$$
\begin{gathered}
n_{i 1}^{M W}=n_{i 1}^{o}=\frac{\bar{y}_{1}-f}{e(K+1)+2 \alpha \sigma_{1}^{2}} \\
n_{i 2}^{M W}=\frac{\bar{w}-f}{e K}
\end{gathered}
$$

Wages associated with these hiring decisions are:

$$
\begin{gathered}
w_{1}^{M W}=w_{1}^{o}=e K \frac{\bar{y}_{1}-f}{e(K+1)+2 \alpha \sigma_{1}^{2}}+f \\
w_{2}^{M W}=\underline{w}
\end{gathered}
$$

Wage effects: Implementation of the minimum wage had no impact on the wages of advantaged workers but did result in an increased wage for disadvantaged workers.

Hiring effects: As for equal pay policy, the minimum wage leads to an increase in employment for disadvantaged workers, even though it targets wages. In the case of advantaged workers, the minimum wage had no effect. The minimum wage artificially increases disadvantaged workers' wages with no impact on advantaged workers. In fact, through this policy, the policymaker changes the marginal cost of the firm to a constant marginal cost. For disadvantaged workers, the effects of an equal pay policy and a minimum wage policy are very similar in terms of wage but opposite in terms of hiring. The crucial difference with the implementation of the minimum wage is that the policymaker sets the wage of disadvantaged workers instead of constraining the whole labour market with an equal pay policy. Therefore, the policymaker maintains control and flexibility in the implementation of policy. However, minimum wage does not imply wage equality since advantaged workers could keep a higher wage if the policymaker decides to set the disadvantaged wage at another (e. g. lower) level.

18 See the appendix for more detailed calculations. 
First-moment and second-moment statistical discrimination: Under minimum wage, the manager only uses the perceived productivity of disadvantage workers to determine how many disadvantage workers to employ. The perceived disadvantage $\left(\bar{y}_{1}-\bar{y}_{2}\right)$ is not directly accounted in this decision. Second-moment statistical discrimination $\left(\sigma_{1} \neq \sigma_{2}\right)$ has no effect on the manager's hiring decision about disadvantage workers when the labour market is imperfectly competitive. In a competitive environment, the manager will take into account the variance of disadvantaged workers' productivity as a negative factor that reduces hiring. The minimum wage reduces and potentially cancels both first and secondmoment statistical discrimination.

Labour market structure effects: Minimum wage appears to be an effective tool to reduce discrimination in the labour market under imperfect competition. First-moment statistical discrimination is drastically reduce and second-moment statistical discrimination disappears. These results do not seem as promising when the labour market is competitive. The minimum wage negatively impacts the employment of disadvantage workers and reinforces the effects of statistical discrimination. Minimum wage is an effective way to combat discrimination in the labour market, only when the labour market is imperfectly competitive.

\subsubsection{Discussion: Advantages and Drawbacks of Public Policies Addressing Wage Discrimination}

Following our theoretical analysis, public policies focusing on wages can reduce or eliminate the pay differential between groups. However, they can potentially create unwanted effects on hiring and employment levels. Policies addressing wages do not alter the return on the labour for the firm, even if wage levels increase because of these policies. The firm is forced to increase the wage of the disadvantaged group which may penalize disadvantaged employment. Minimum wage does not suffer such negative effects when applied in an imperfectly competitive labour market. According to the results of our model, the legislator should prefer minimum wage to equal pay to combat first and secondmoment statistical discrimination, especially if facing imperfect competition in the labour market.

This theoretical model corroborates research by Cornell and Welch (1996) who suggest that disadvantaged employment could be reduced by an equal pay policy, as well as, the empirical results from Neumark and Stock (2006) based on state sex discrimination laws targeting discrimination in pay only (equal pay). Our model indicates that a misdirected policy can have negative effects on both 
the wages and the hiring of workers in the advantaged group. Consequently, public policies that address wages appear questionable as their implementation could have numerous unwanted effects.

\subsection{Public Policies Addressing Hiring Discrimination}

\subsubsection{Quotas}

A quota system is a classic policy that governments use to reduce hiring discrimination. Firms face the constraint of having at least a fixed proportion of disadvantaged workers on the payroll. In this section, we present a strict quota prescribing firms to have disadvantaged and advantaged groups in the same proportion: $n_{1}=n_{2}=n$. ${ }^{19}$ We conclude that a quota causes the convergence of hiring values and wage values in the advantaged and disadvantaged groups. Let $n$ be the number of workers in each group. The maximization problem becomes:

$$
\max _{n_{i}} \sum_{j=1}^{2} n_{i} \bar{y}_{j}-2 n_{i}\left(f+e n_{i}+e \sum_{k \neq i} n_{k}\right)-\alpha n_{i}^{2} \sum_{j=1}^{2} \sigma_{j}^{2} .
$$

Optimal hiring decisions are: ${ }^{20}$

$$
n_{i}^{\prime}=\frac{\frac{\bar{y}_{1}+\bar{y}_{2}}{2}-f}{e(K+1)+\alpha \sum_{j=1}^{2} \sigma_{j}^{2}}
$$

Wages associated with these hiring decisions are:

$$
w_{1}=w_{2}=w^{\prime},=e K \frac{\frac{\bar{y}_{1}+\bar{y}_{2}}{2}-f}{e(K+1)+\alpha \sum_{j=1}^{2} \sigma_{j}^{2}}+f
$$

Wage effects: The quota policy seems to have an unexpected effect - equal pay! ${ }^{21}$ The single wage ends up with a value between the baseline wages. If the quota is less strict than hiring equality but is still a constraint, the pay gap is reduced. Whatever the case, a quota policy results in a convergence of wages for the disadvantaged and advantaged groups.

19 We could also easily apply this model to quotas with less strict proportions prescribed $\left(n_{2} \geq \theta n_{1}\right)$; the results and their interpretation would not change much.

20 See the appendix for more detailed calculations.

21 This result strongly depends on the assumption that advantaged and disadvantaged workers have the same labour supply; however, when we relax this assumption, the model predicts convergence. 
Hiring effects: The policy in our model imposes strict equality of hiring in the two groups. The result is that the wages of the two groups converge to an intermediate value located between the original hiring values in the baseline model: $n_{i 2}^{\star} \leq n_{i}^{\prime}$ ' $\leq n_{i 1}^{\star}$. A less strict quota would result in convergence. The proportion of disadvantaged workers would exactly correspond to the minimum prescribed by the quota.

Implementation of the quota changes the labour value for the firm. The firm cannot continue to hire workers on a one-by-one basis; it has to hire workers two at a time (one from each group). In other words, if the firm wants an advantaged worker, it also has to hire a disadvantaged worker. The firm's demand is then affected, and both baseline demands converge to two combined and intermediate labour demands. The effect on wages of the quota is expressed through the labour supply. On one hand, the firm has to stimulate the participation of disadvantaged workers in the labour market to fulfill its need for workers. The only way is to increase the disadvantaged wage to hire more disadvantaged workers. On the other hand, after $n$ ', the firm does not want more advantaged workers because hiring two workers becomes too costly. Furthermore, because $n_{i 1}^{*}>n_{i}^{\prime}$, the firm does not need as many advantaged workers as in the baseline model. The advantaged wage decreases to the same level as the disadvantaged one. These findings closely match effects exposed in Welch (1976). The main difference being that equal pay is the result of our model, whereas in Welch (1976) it is an assumption. ${ }^{22}$ Our model also rounds out the findings of Welch (1976) by illustrating the income redistribution mechanism. In fact, we can state that the policy forces the firm to uniformly share perceived productivity and risks differentials in workers' wage. Consequently, advantaged workers become responsible for a part of the firm's beliefs about disadvantaged workers. The effect on total hiring and on total production depends upon the values of $\sigma_{1}^{2}$ and $\sigma_{2}^{2}$; the effects are not always similar.

First-moment and second-statistical discrimination: Quota forces the manager to average out uniformly perceived productivity and risk differences. In other words, quota hides first and second-moment statistical discrimination since it equally shares their effects between all the workers. First-moment and second-statistical discrimination become unobservable under a quota regime.

22 Welch (1976) assumes that firms must pay the same wage to all workers who have the same job title. He finds that quotas redistribute income from majority to minority workers. 
Labour market structure effects: The efficiency of a quota is not affected when the labour market structures varies.

\subsubsection{Subsidy per Disadvantaged Worker}

This section examines the effect a government subsidy would have on firms for employment of each disadvantaged worker. The goal of such a policy is to stimulate the hiring of disadvantaged workers through a direct transfer of funds. The policy we present in this section is related to the idea of differential taxation introduced by Alberto Alesina and Andrea Ichino in their article "Why women should pay less tax" in the Financial Times of April 18, 2007. They suggest reducing income tax for women and increasing, to a lesser degree, income tax for men. Their goal is to stimulate the participation rate of women in the labour market. However, this is not our goal, though we wish to maintain the notion of government intervention based on gender. We focus on the firm's hiring behaviour and how disadvantaged workers can be made more attractive to the firm. Our subsidy supports governments' and policymakers' heterogeneous treatment of various groups to foster disadvantaged employment. For the remainder of this paper, this subsidy policy will be called the " $\tau$ policy". In order to verify its effectiveness, we add the compensation transfer $\tau$ to the profit function. This yields the following maximization program:

$$
\max _{n_{1}, n_{2}} \sum_{j=1}^{2} n_{i j}\left[\bar{y}_{j}-f-e\left(n_{i j}+\sum_{k \neq j} n_{k j}\right)+(j-1) \tau\right]-\alpha \sum_{j=1}^{2} n_{j}^{2} \sigma_{j}^{2} .
$$

Optimal hiring decisions are: ${ }^{23}$

$$
\begin{gathered}
n_{1}^{\tau}=n_{1}^{o}=\frac{\bar{y}_{1}-f}{e(K+1)+2 \alpha \sigma_{1}^{2}}, \\
n_{2}^{\tau}=\frac{\bar{y}_{2}-f+\tau}{e(K+1)+2 \alpha \sigma_{2}^{2}} .
\end{gathered}
$$

Wages associated with these hiring decisions are:

$$
w_{1}^{\tau}=w_{1}^{o}=e K \frac{\bar{y}_{1}-f}{e(K+1)+2 \alpha \sigma_{1}^{2}}+f,
$$

23 See the appendix for more detailed calculations. 


$$
w_{2}^{\tau}=e K \frac{\bar{y}_{2}-f+\tau}{e(K+1)+2 \alpha \sigma_{2}^{2}}+f .
$$

There is a value $\tau^{\star}$ which can eliminate wage and hiring discrimination in the labour market: ${ }^{24}$

$$
\tau^{\star}=\frac{e(K+1)\left(\bar{y}_{1}-\bar{y}_{2}\right)+2 \alpha\left(\sigma_{2}^{2} \bar{y}_{1}-\sigma_{1}^{2} \bar{y}_{2}\right)-2 \alpha f\left(\sigma_{2}^{2}-\sigma_{1}^{2}\right)}{e(K+1)+2 \alpha \sigma_{1}^{2}} .
$$

Wage effects: The $\tau$ policy seems to have no wage consequence on advantaged workers yet increases wages of disadvantaged workers. If the subsidy is well calibrated (at $\tau^{\star}$ ), it results in equal pay. The value of the wage is equal to the baseline wage of advantaged workers. The subsidy makes it possible to increase the disadvantaged wage to the level of the advantaged wage; no other policy analyzed in this paper makes this possible.

Hiring effects: The $\tau$ policy increases disadvantaged hiring while having no impact on advantaged employment. If the subsidy is well calibrated (at $\tau^{\star}$ ), the disadvantaged employment level matches the advantaged employment baseline level; this possibility did not occur with other policies analyzed in this paper.

First and Second-moment statistical discrimination: The $\tau$ policy compensates the firm for any perceived productivity and risk differentials and therefore cancels out first and second-moment statistical discrimination.

Labour market structure effects: The efficiency of the $\tau$ policy is unaffacted by the labour market structure.

\subsubsection{Social Cost}

It is incumbent to examine the social cost of this policy as it imposes a monetary cost on the government. In addition to the direct cost of the policy, we must also consider the government's unemployment insurance payment that disadvantage workers will not require once employed.

Firms and Workers This policy helps to eradicate discriminatory phenomena. There is no impact on advantaged workers yet the conditions of disadvantaged workers improve because both wages and hiring increase. The welfare of the

24 See the appendix for more detailed calculations. 
firm increases because it can produce more with no additional cost (the subsidy pays the additional costs). Both workers and the firm show positive returns following implementation of the $\tau$ policy.

Social Welfare The $\tau$ policy could be socially beneficial. Uncertainty remains, however, in terms of the net benefit for the government. The government gains by granting subsidy because the decrease in unemployment payments could be greater than the total value of the subsidy. We cannot make conclusions about the direction of social welfare in this case. Therefore, to determine the variation in the value of social welfare:

$$
\begin{aligned}
\Delta S & =\Delta W+\Delta F+\Delta G \\
& =>0+>0+?
\end{aligned}
$$

The determination rule in the model is:

$$
\begin{gathered}
\left\{\begin{array}{c}
\text { If } \Delta G>0 \\
\text { or If } \Delta G=0 \\
\text { or If }\left\{\begin{array}{c}
\Delta G<0 \\
\text { and }|\Delta G| \leq \Delta W+\Delta F
\end{array}\right\}
\end{array}\right\} \Rightarrow \text { Socially Beneficial } \\
\text { If }\left\{\begin{array}{c}
\Delta G<0 \\
\text { and }|\Delta G|>\Delta W+\Delta F
\end{array}\right\} \Rightarrow \text { Not Socially Beneficial }
\end{gathered}
$$

We show that this policy could be socially beneficial, with some conditions. Implementation is fairly easy since governments already use subsidies to firms. Another way of implementing this policy would be to reduce taxation on disadvantaged employment. The main challenge is to evaluate the amount of the subsidies. The dollar value depends on differential beliefs making it difficult for the government to establish the exact value.

Implementation of the $\tau$ policy changes the value of disadvantaged workers for the firm because the government gives a dollar amount for each disadvantaged worker hired. Disadvantaged workers appear cheaper than they really are. Therefore, the labour demand of the firm for disadvantaged workers increases. If the government decides to give $\tau^{\star}$, the labour demands for disadvantaged and advantaged workers merge. Then disadvantaged and advantaged workers are viewed in exactly the same way by the firm. Therefore, no discriminatory phenomena occur with $\tau^{\star}$. It is important to note that the philosophy of this policy is very different than previously examined policies. Other policies act as a constraint on the firm to reduce discrimination. The $\tau$ policy is different in the sense that the policymaker does not impose a constraint on firms. It uses an 
incentive for the firm to change hiring behaviour. The limitation of this policy could be the social cost because the government has to pay the subsidy $\tau^{\star}$ and funding needs are created. ${ }^{25}$

\subsection{Discussion: Advantages and Disadvantages of Public Policies Addressing Hiring Discrimination}

Both quota and subsidy policies are directly impacting the labour demand and changing the value of workers for firms. With these policies, the government has two different tools: one involving a constraint (quota) and the other involving an incentive (subsidy). They have the same effects when we only focus on discriminatory phenomena, i. e. reducing or eliminating wage and hiring discrimination. However, when the focus is also on wage and hiring values, the subsidy allows for more flexibility and has a less negative effect on advantaged workers. In fact, the subsidy allows the government to increase the labour demand for disadvantaged workers while the quota converges the labour demands for both groups. The subsidy provides more flexibility for the government to incite firms to employ more disadvantaged workers and to pay them more, while having less of a negative impact on the advantaged workers.

The advantages of public policies addressing hiring behaviour are clear they effectively act on both of the front lines of discrimination (wage and hiring). Additionally, the labour market structures do not affect the efficiency of policies targeting hiring practices, which means they would be effective in any labour market if calibrated properly. However, depending on the policy, they have various drawbacks which must be taken into account. Our suggested incentive policy (disadvantaged employment subsidy) leads to interesting results when compared to policies that impose constraints on the managers (equal pay, quota and minimum wage) but it introduces monetary transfers which may become prohibitive. Such policy might have to be restricted to low productivity industries. Indeed, moving from constraint type policies to incentive policies potentially leads to better results, as the firm is incorporated into the solution, yet more research is needed in this area. Being a major player in the labour market, the firm should not be considered an enemy or problem by policymakers.

25 We chose not to add a tax to finance the subsidy because of the negative effect it would have on employment. 


\section{Should a Public Policy Target Wages or Hiring?}

The key difference between the wage and hiring policies is the impact on the workers' value for the firm. Policies on wages such as minimum wage and equal pay change only the market price of workers but not the firm's labour demand. In addition, wage policies create unemployment among disadvantaged workers and a shortage of advantaged workers. Policies on hiring behaviour, such as quotas and subsidies, change the way managers consider workers. The whole approach to hiring is affected and so is firm's labour demand. Moreover, our model shows that instead of constraining the firm, the subsidy policy provides an incentive for firms to reduce discrimination, whereas a wage policy cannot do this. However, incentive-oriented policies create a monetary cost that the government has to cover. Also, policies on hiring behaviour will not be influenced by labour market structure. They are as effective with either competition, oligopsony or monopsony. Conversely, the efficiency of policies impacting wages can change depending on the market structure. They especially lose efficiency in a competitive labour market. It seems to us that policies targeting hiring behaviours, namely quotas and subsidies, provide more effective anti-discriminatory policies and fairer results even given their drawbacks.

\section{First, Second-Moment Statistical Discrimination and Risk-Aversion}

As stated in introduction, the traditional first-moment statistical discrimination models are incomplete and the addition of managers' risk-aversion and secondmoment statistical discrimination could explain, at least in part, the discriminatory phenomena observed in the labour market. One of the aims of this paper was to highlight that failing to consider risk-aversion and second-moment statistical discrimination could be problematic when designing solutions to combat discrimination in the labour market.

Our theoretical models show that risk-aversion and second-moment statistical discrimination not only reinforce the distortion caused by the first-moment of discrimination but also create additional differences that would not be explained without considering them. Second-moment statistical discrimination is "self-sufficient" since it does not require first-moment statistical discrimination. When we adapt the model for only second-moment statistical discrimination $\left(\bar{y}_{1}=\bar{y}_{2}\right)$, all the effects described previously still exist. This means the model provides a robust explanation for equally productive workers being 
paid and hired in different proportions. The results obtained when analyzing different labour market structures and public policies are maintained.

We identified potential calibration problems for a government that would combat discrimination if second-moment statistical discrimination was omitted. Potential perverse effects of policies could be understated or ignored. Perverse effects potentially affect both advantaged and disadvantaged workers. This issue is relevant because quota and equal pay are not successful in cancelling discrimination in the labour market; governments need more sophisticated technics to achieve this goal. As illustrated in our proposed policies, more sophistication means policies requiring precise calibration. ${ }^{26}$ This further justifies the need to thoroughly understand the different effects at play including managers' risk-aversion and second-moment statistical discrimination.

\section{Conclusion}

In addition to providing a theoretical analysis of the effects of public policies and labour market structures on discrimination, this paper raises questions about certain methods employed to combat discrimination. We have shown discrimination is impacted differently when a policy addresses hiring behaviour or wages, and if it adds a constraint on the firm, or provides an incentive. We considered both wage and hiring components in our models because their interdependence is critical. Their interdependence could lead to unwanted effects which policymakers should take into consideration when implementing policies. Our results show that the negative impact of certain policies are significant enough to be warrant consideration in the decision-making process of policymakers. Indeed, all possible effects should be scrutinized when designing a policy that will become law. Given the above, we believe that a number of current government policies do not redress inequality in the labour market and that new solutions, perhaps those we have illustrated in this paper, will be more effective in correcting wage and hiring discrimination.

A limitation of the models presented above is that they do not consider endogenous entry/exit of firms. The addition of endogenous entry and exit to the models may alter some of the policy results obtained in the competitive and oligopsonic cases. The implementation of anti-discrimination policies may

26 Finding the right level for the minimum wage and the right amount for the subsidy. 
decrease firms' profits. A reduction of profits might increase the degree of monopsony power through the entry/exit process, and therefore, may reinforce discrimination. The addition of endogenous entry/exit would be a useful extension of these models and could be an avenue for further research.

Acknowledgements: I would like to thank Robert Clark and Nicolas Sahuguet for their numerous helpful suggestions, Faithe Picault and the anonymous referees for the constructive input, thank the departments of economics at the University of Western Ontario and HEC Montréal for hospitality and the excellent research conditions, and gratefully acknowledge financial support from foundation Roger Charbonneau, CIRPÉE, and HEC Montréal.

\section{Appendix}

\section{A.1 Monopsony Model}

\section{A.1.1 General Form}

The inverse labour supply is: $w_{j}=g\left(n_{j}\right)$ with $g^{\prime}\left(n_{j}\right) \leq 0$. The utility function of profit of the firm is:

$$
U\left[E\left(\pi\left(n_{j} ; w_{j}\right)\right) ; \alpha \operatorname{Var}\left(\pi\left(n_{j} ; w_{j}\right)\right)\right]
$$

with $U_{E} \geq 0$ and $U_{V} \leq 0$.

The optimal hiring behavior is determined by the following maximisation program:

$$
\begin{gathered}
\max _{n_{j} ; w_{j}} U\left[E\left(\pi\left(n_{j} ; w_{j}\right)\right) ; \alpha \operatorname{Var}\left(\pi\left(n_{j} ; w_{j}\right)\right)\right] \\
\text { s.t. }\left\{\begin{array}{c}
w_{j}=g\left(n_{j}\right) \\
\left.\pi\left(n_{j} ; w_{j}\right)=\sum_{j=1}^{2}\left[n_{j}\left(y_{j}-w_{j}\right)\right]^{\nabla j}\right\} .
\end{array}\right.
\end{gathered}
$$

This yields the first order conditions of the problem:

$$
U_{E}\left(n_{j}\right)\left[\bar{y}_{j}-g\left(n_{j}\right)-g^{\prime}\left(n_{j}\right) n_{j}\right]+2 \alpha n_{j} \sigma_{j}^{2} U_{v}\left(n_{j}\right)=0 \text { and } w_{j}=g\left(n_{j}\right) .
$$

The first order conditions have the same properties as those in the baseline model (reduced forms). 


\section{A.1.2 Baseline Model}

$$
\begin{array}{ll} 
& \max _{n_{1}, n_{2}} n_{1}\left(\bar{y}_{1}-f-e n_{1}\right)+n_{2}\left(\bar{y}_{2}-f-e n_{2}\right)-\alpha\left(n_{1}^{2} \sigma_{1}^{2}+n_{2}^{2} \sigma_{2}^{2}\right) \\
\Leftrightarrow \frac{\partial-}{\partial n_{1}}=0 & \Leftrightarrow \frac{\partial-}{\partial n_{2}}=0 \\
\Leftrightarrow \bar{y}_{1}-2 e n_{1}-f-2 \alpha n_{1} \sigma_{1}^{2}=0 & \Leftrightarrow \bar{y}_{2}-2 e n_{2}-f-2 \alpha n_{2} \sigma_{2}^{2}=0 \\
\Leftrightarrow n_{1}^{\star}=\frac{\bar{y}_{1}-f}{2\left(e+\alpha \sigma_{1}^{2}\right)} & \Leftrightarrow n_{2}^{\star}=\frac{\bar{y}_{2}-f}{2\left(e+\alpha \sigma_{2}^{2}\right)} \\
\Rightarrow w_{1}^{*}=e \frac{\bar{y}_{1}-f}{2\left(e+\alpha \sigma_{1}^{2}\right)}+f & \Rightarrow w_{2}^{\star}=e \frac{\bar{y}_{2}-f}{2\left(e+\alpha \sigma_{2}^{2}\right)}+f
\end{array}
$$

\section{A.1.3 Baseline model if $y_{1}$ and $y_{2}$ are correlated}

$$
\begin{array}{ll}
\max _{n_{1}, n_{2}} n_{1}\left(\bar{y}_{1}-f-e n_{1}\right)+n_{2}\left(\bar{y}_{2}-f-e n_{2}\right)-\alpha\left(n_{1}^{2} \sigma_{1}^{2}+n_{2}^{2} \sigma_{2}^{2}+2 n_{1} n_{2} \sigma_{12}\right) \\
\Leftrightarrow \frac{\partial-}{\partial n_{1}}=0 & \Leftrightarrow \frac{\partial-}{\partial n_{2}}=0 \\
\Leftrightarrow \bar{y}_{1}-2 e n_{1}-f-2 \alpha n_{1} \sigma_{1}^{2}-2 \alpha n_{2} \sigma_{12}=0 & \Leftrightarrow \bar{y}_{2}-2 e n_{2}-f-2 \alpha n_{2} \sigma_{2}^{2}-2 \alpha n_{1} \sigma_{12}=0 \\
\Leftrightarrow n_{1}=\frac{\bar{y}_{1}-f-2 \alpha n_{2} \sigma_{12}}{2\left(e+\alpha \sigma_{1}^{2}\right)} & \Leftrightarrow n_{2}=\frac{\bar{y}_{2}-f-2 \alpha n_{1} \sigma_{12}}{2\left(e+\alpha \sigma_{2}^{2}\right)} \\
\Leftrightarrow n_{1}^{\star *}=\frac{\left(\bar{y}_{1}-f\right)\left[e+\alpha \sigma_{2}^{2}-\alpha \sigma_{12}\right]}{2\left(e+\alpha \sigma_{1}^{2}\right)\left(e+\alpha \sigma_{2}^{2}\right)+\alpha \sigma_{12}} & \Leftrightarrow n_{2}^{\star \star}=\frac{\left(\bar{y}_{2}-f\right)\left[e+\alpha \sigma_{1}^{2}-\alpha \sigma_{12}\right]}{2\left(e+\alpha \sigma_{1}^{2}\right)\left(e+\alpha \sigma_{2}^{2}\right)+\alpha \sigma_{12}} \\
\Leftrightarrow w_{1}^{\star *}=e \frac{\left(\bar{y}_{1}-f\right)\left[e+\alpha \sigma_{2}^{2}-\alpha \sigma_{12}\right]}{2\left(e+\alpha \sigma_{1}^{2}\right)\left(e+\alpha \sigma_{2}^{2}\right)+\alpha \sigma_{12}}+f & \Leftrightarrow w_{2}^{\star *}=e \frac{\left(\bar{y}_{2}-f\right)\left[e+\alpha \sigma_{1}^{2}-\alpha \sigma_{12}\right]}{2\left(e+\alpha \sigma_{1}^{2}\right)\left(e+\alpha \sigma_{2}^{2}\right)+\alpha \sigma_{12}}+f
\end{array}
$$

We therefore obtain the same properties as those of the uncorrelated case.

\section{A.2 Oligopsony Model with Symmetrical Firms}

$$
\begin{array}{ll}
\max _{n_{i 1}, n_{i 2}} n_{i 1}\left[\bar{y}_{1}-f-e\left(n_{i 1}+\sum_{k \neq j} n_{k 1}\right)\right] & +n_{i 2}\left[\bar{y}_{2}-f-e\left(n_{i 2}+\sum_{k \neq j} n_{k 2}\right)\right] \\
& -\alpha\left(n_{i 1}^{2} \sigma_{1}^{2}+n_{i 2}^{2} \sigma_{2}^{2}\right) \\
\Leftrightarrow \frac{\partial-}{\partial n_{i 1}}=0 & \Leftrightarrow \frac{\partial-}{\partial n_{i 2}}=0 \\
\Leftrightarrow \bar{y}_{1}-2 e n_{i 1}-f-2 \alpha n_{i 1} \sigma_{1}^{2}-e \sum_{k \neq j} n_{k 1}=0 & \Leftrightarrow \bar{y}_{2}-2 e n_{i 2}-f-2 \alpha n_{i 2} \sigma_{2}^{2}-e \sum_{k \neq j} n_{k 2}=0 \\
\Leftrightarrow n_{i 1}^{o}=\frac{\bar{y}_{1}-f}{e(K+1)+2 \alpha \sigma_{1}^{2}} & \Leftrightarrow n_{i 2}^{o}=\frac{\bar{y}_{2}-f}{e(K+1)+2 \alpha \sigma_{2}^{2}} \\
\Rightarrow w_{1}^{o}=e K \frac{\bar{y}_{1}-f}{e(K+1)+2 \alpha \sigma_{1}^{2}}+f & \Rightarrow w_{i 2}^{o}=e K \frac{\bar{y}_{2}-f}{e(K+1)+2 \alpha \sigma_{2}^{2}}+f
\end{array}
$$




\section{A.3 Competitive Market Structure Model}

$$
\begin{array}{ll}
\max _{n_{i 1}, n_{i 2}} n_{i 1}\left(\bar{y}_{1}-w_{1}\right)+n_{i 2}\left(\bar{y}_{2}-w_{2}\right)-\alpha\left(n_{i 1}^{2} \sigma_{1}^{2}+n_{i 2}^{2} \sigma_{2}^{2}\right) \\
\Leftrightarrow \frac{\partial-}{\partial n_{i 1}}=0 & \Leftrightarrow \frac{\partial-}{\partial n_{i 2}}=0 \\
\Leftrightarrow \bar{y}_{1}-w_{1}-2 \alpha n_{1} \sigma_{1}^{2}=0 & \Leftrightarrow \bar{y}_{2}-w_{2}-2 \alpha n_{2} \sigma_{2}^{2}=0 \\
\Leftrightarrow n_{i 1}=\frac{\bar{y}_{1}-w_{1}}{2 \alpha \sigma_{1}^{2}} & \Leftrightarrow n_{i 2}=\frac{\bar{y}_{2}-w_{2}}{2 \alpha \sigma_{2}^{2}}
\end{array}
$$

In the labour market with symmetrical firms, we have:

$$
\begin{array}{ll}
\left\{\begin{array}{c}
n_{i 1}=\frac{\bar{y}_{1}-w_{1}}{2 \alpha \sigma_{1}^{2}} \\
w_{i 1}=e L n_{i 1}+f
\end{array}\right\} \quad\left\{\begin{array}{c}
n_{i 2}=\frac{\bar{y}_{2}-w_{2}}{2 \alpha \sigma_{2}^{2}} \\
w_{i 2}=e L n_{i 2}+f
\end{array}\right\} \\
\Leftrightarrow n_{i 1}^{c}=\frac{\bar{y}_{1}-f}{e L+2 \alpha \sigma_{1}^{2}} & \Leftrightarrow n_{i 2}^{c}=\frac{\bar{y}_{2}-f}{e L+2 \alpha \sigma_{2}^{2}} \\
\Rightarrow w_{1}^{c}=e L \frac{\bar{y}_{1}-f}{e L+2 \alpha \sigma_{1}^{2}}+f \quad & \Rightarrow w_{i 2}^{c}=e L \frac{\bar{y}_{2}-f}{e L+2 \alpha \sigma_{2}^{2}}+f
\end{array}
$$

\section{A.3.1 Equal Pay Model}

\section{Oligopsony}

$$
\begin{array}{ccc}
\max _{n_{1}, n_{2}} n_{i 1} \bar{y}_{1}+n_{i 2} \bar{y}_{2}-\left(n_{i 1}+n_{i 2}\right)\left(f+\frac{e}{2}\left(n_{i 1}+n_{i 2}+\sum_{k \neq j} n_{k 1}+\sum_{k \neq j} n_{k 2}\right)\right) & -\alpha\left(n_{i 1}^{2} \sigma_{1}^{2}+n_{i 2}^{2} \sigma_{2}^{2}\right) & \Leftrightarrow \frac{\partial-}{\partial n_{i 2}}=0 \\
\Leftrightarrow \frac{\partial-}{\partial n_{i 1}}=0 & \Leftrightarrow \bar{y}_{2}-f-e\left(n_{i 1}+n_{i 2}\right)-\frac{e}{2}\left(\sum_{k \neq j} n_{k 1}\right. \\
\Leftrightarrow \bar{y}_{1}-f-e\left(n_{i 1}+n_{i 2}\right)-\frac{e}{2}\left(\sum_{k \neq j} n_{k 1}\right. & \left.+\sum_{k \neq j} n_{k 2}\right)-2 \alpha n_{i 2} \sigma_{2}^{2}=0 \\
\left.+\sum_{k \neq j} n_{k 2}\right)-2 \alpha n_{i 1} \sigma_{1}^{2}=0 & \Leftrightarrow n_{i 2}\left(2 \alpha \sigma_{2}^{2}+\frac{e}{2}(K+1)\right) \\
\Leftrightarrow n_{i 1}\left(2 \alpha \sigma_{1}^{2}+\frac{e}{2}(K+1)\right) & =\bar{y}_{2}-f-\frac{e}{2}(K+1) n_{i 1} \\
=\bar{y}_{1}-f-\frac{e}{2}(K+1) n_{i 2} & n_{i 2}^{\prime}=\frac{2 \sigma_{1}^{2}\left(\bar{y}_{2}-f\right)}{\alpha \sigma_{1}^{2} \sigma_{2}^{2}+e(K+1)\left(\sigma_{1}^{2}+\sigma_{2}^{2}\right)} \\
\Rightarrow n_{i 1}^{\prime}=\frac{2 \sigma_{2}^{2}\left(\bar{y}_{1}-f\right)}{\alpha \sigma_{1}^{2} \sigma_{2}^{2}+e(K+1)\left(\sigma_{1}^{2}+\sigma_{2}^{2}\right)} & -\frac{e(K+1)\left(\bar{y}_{1}-\bar{y}_{2}\right)}{2 \alpha\left[2 \alpha \sigma_{1}^{2} \sigma_{2}^{2}+e(K+1)\left(\sigma_{1}^{2}+\sigma_{2}^{2}\right)\right]} \\
+\frac{e(K+1)\left(\bar{y}_{1}-\bar{y}_{2}\right)}{2 \alpha\left[2 \alpha \sigma_{1}^{2} \sigma_{2}^{2}+e(K+1)\left(\sigma_{1}^{2}+\sigma_{2}^{2}\right)\right]} & w^{\prime}=e K \frac{\bar{y}_{1} \sigma_{2}^{2}+\bar{y}_{2} \sigma_{1}^{2}-f\left(\sigma_{1}^{2}+\sigma_{2}^{2}\right)}{2 \alpha \sigma_{1}^{2} \sigma_{2}^{2}+e(K+1)\left(\sigma_{1}^{2}+\sigma_{2}^{2}\right)}+f
\end{array}
$$

In verifying the labour supply of advantaged workers, it appears that there is an insufficient number of workers available to work at this wage. The 
number of workers from the advantaged group who would accept to work at this wage is:

$$
n_{i 1}^{\prime}=\frac{\bar{y}_{1} \sigma_{2}^{2}+\bar{y}_{2} \sigma_{1}^{2}-f\left(\sigma_{1}^{2}+\sigma_{2}^{2}\right)}{2 \alpha \sigma_{1}^{2} \sigma_{2}^{2}+e(K+1)\left(\sigma_{1}^{2}+\sigma_{2}^{2}\right)}
$$

\section{Monopsony}

$$
\begin{array}{cc}
\max _{n_{1}, n_{2}} n_{1} \bar{y}_{1}+n_{2} \bar{y}_{2}-\left(n_{1}+n_{2}\right)\left(f+\frac{e}{2}\left(n_{1}+n_{2}\right)\right)-\alpha\left(n_{1}^{2} \sigma_{1}^{2}+n_{2}^{2} \sigma_{2}^{2}\right) \\
\Leftrightarrow \frac{\partial-}{\partial n_{1}}=0 & \Leftrightarrow \frac{\partial-}{\partial n_{2}}=0 \\
\Leftrightarrow \bar{y}_{1}-\frac{e}{2}\left(2 n_{1}+2 n_{2}\right)-f-2 \alpha n_{1} \sigma_{1}^{2}=0 & \Leftrightarrow \bar{y}_{2}-\frac{e}{2}\left(2 n_{1}+2 n_{2}\right)-f-2 \alpha n_{2} \sigma_{2}^{2}=0 \\
\Leftrightarrow n_{1}\left(2 \alpha \sigma_{1}^{2}+e\right)=\bar{y}_{1}-f-e n_{2} & \Leftrightarrow n_{2}\left(2 \alpha \sigma_{2}^{2}+e\right)=\bar{y}_{2}-f-e n_{1} \\
\Rightarrow n_{1}^{\prime}=\frac{\sigma_{2}^{2}\left(\bar{y}_{1}-f\right)}{2 \alpha \sigma_{1}^{2} \sigma_{2}^{2}+e\left(\sigma_{1}^{2}+\sigma_{2}^{2}\right)} & \Rightarrow n_{2}^{\prime}=\frac{\sigma_{1}^{2}\left(\bar{y}_{2}-f\right)}{2 \alpha \sigma_{1}^{2} \sigma_{2}^{2}+e\left(\sigma_{1}^{2}+\sigma_{2}^{2}\right)} \\
+\frac{e\left(\bar{y}_{1}-\bar{y}_{2}\right)}{2 \alpha\left[2 \alpha \sigma_{1}^{2} \sigma_{2}^{2}+e\left(\sigma_{1}^{2}+\sigma_{2}^{2}\right)\right]} & -\frac{e\left(\bar{y}_{1}-\bar{y}_{2}\right)}{2 \alpha\left[2 \alpha \sigma_{1}^{2} \sigma_{2}^{2}+e\left(\sigma_{1}^{2}+\sigma_{2}^{2}\right)\right]} \\
w^{\prime}=\frac{e}{2} \frac{\bar{y}_{1} \sigma_{2}^{2}+\bar{y}_{2} \sigma_{1}^{2}-f\left(\sigma_{1}^{2}+\sigma_{2}^{2}\right)}{2 \alpha \sigma_{1}^{2} \sigma_{2}^{2}+e\left(\sigma_{1}^{2}+\sigma_{2}^{2}\right)}+f
\end{array}
$$

In verifying the labour supply of advantaged workers, it appears that there is an insufficient number of workers available to work at this wage. The number of workers from the advantaged group who would accept to work at this wage is:

$$
n_{1}^{\prime}=\frac{1}{2} \frac{\bar{y}_{1} \sigma_{2}^{2}+\bar{y}_{2} \sigma_{1}^{2}-f\left(\sigma_{1}^{2}+\sigma_{2}^{2}\right)}{2 \alpha \sigma_{1}^{2} \sigma_{2}^{2}+e\left(\sigma_{1}^{2}+\sigma_{2}^{2}\right)}
$$

\section{Competition}

$$
\begin{array}{ll}
\max _{n_{i 1}, n_{i 2}} n_{i 1}\left(\bar{y}_{1}-w\right)+n_{i 2}\left(\bar{y}_{2}-w\right)-\alpha\left(n_{i 1}^{2} \sigma_{1}^{2}+n_{i 2}^{2} \sigma_{2}^{2}\right) \\
\Leftrightarrow \frac{\partial-}{\partial n_{i 1}}=0 & \Leftrightarrow \frac{\partial-}{\partial n_{i 2}}=0 \\
\Leftrightarrow \bar{y}_{1}-w-2 \alpha n_{1} \sigma_{1}^{2}=0 & \Leftrightarrow \bar{y}_{2}-w-2 \alpha n_{2} \sigma_{2}^{2}=0 \\
\Leftrightarrow n_{i 1}=\frac{\bar{y}_{1}-w}{2 \alpha \sigma_{1}^{2}} & \Leftrightarrow n_{i 2}=\frac{\bar{y}_{2}-w}{2 \alpha \sigma_{2}^{2}}
\end{array}
$$

In the labour market with symmetrical firms, we have:

$$
\begin{gathered}
\left\{\begin{array}{c}
n_{i 1}=\frac{\bar{y}_{1}-w_{1}}{2 \alpha \sigma_{1}^{2}} \\
w=\frac{e L}{2}\left(n_{i 1}+n_{i 2}\right)+f
\end{array}\right\} \\
\Leftrightarrow n_{1}\left(2 \alpha \sigma_{1}^{2}+e L\right)=\bar{y}_{1}-f-e L n_{2} \\
\Rightarrow n_{1}^{\prime}=\frac{\sigma_{2}^{2}\left(\bar{y}_{1}-f\right)}{2 \alpha \sigma_{1}^{2} \sigma_{2}^{2}+e L\left(\sigma_{1}^{2}+\sigma_{2}^{2}\right)} \\
\quad+\frac{e L\left(\bar{y}_{1}-\bar{y}_{2}\right)}{2 \alpha\left[2 \alpha \sigma_{1}^{2} \sigma_{2}^{2}+e L\left(\sigma_{1}^{2}+\sigma_{2}^{2}\right)\right]}
\end{gathered}
$$$$
\left\{\begin{array}{c}
n_{i 2}=\frac{\bar{y}_{2}-w_{2}}{2 \alpha \sigma_{2}^{2}} \\
w=\frac{e L}{2}\left(n_{i 1}+n_{i 2}\right)+f
\end{array}\right\}
$$$$
\Leftrightarrow n_{2}\left(2 \alpha \sigma_{2}^{2}+e L\right)=\bar{y}_{2}-f-e L n_{1}
$$$$
\Rightarrow n_{2}^{\prime}=\frac{\sigma_{1}^{2}\left(\bar{y}_{2}-f\right)}{2 \alpha \sigma_{1}^{2} \sigma_{2}^{2}+e L\left(\sigma_{1}^{2}+\sigma_{2}^{2}\right)}
$$$$
-\frac{e l\left(\bar{y}_{1}-\bar{y}_{2}\right)}{2 \alpha\left[2 \alpha \sigma_{1}^{2} \sigma_{2}^{2}+e L\left(\sigma_{1}^{2}+\sigma_{2}^{2}\right)\right]}
$$ 


$$
w^{\prime}=\frac{e L}{2} \frac{\bar{y}_{1} \sigma_{2}^{2}+\bar{y}_{2} \sigma_{1}^{2}-f\left(\sigma_{1}^{2}+\sigma_{2}^{2}\right)}{2 \alpha \sigma_{1}^{2} \sigma_{2}^{2}+e L\left(\sigma_{1}^{2}+\sigma_{2}^{2}\right)}+f
$$

In verifying the labour supply of advantaged workers, it appears that there is an insufficient number of workers available to work at this wage. The number of workers from the advantaged group who would accept to work at this wage is:

$$
n_{i 1}=\frac{\bar{y}_{1} \sigma_{2}^{2}+\bar{y}_{2} \sigma_{1}^{2}-f\left(\sigma_{1}^{2}+\sigma_{2}^{2}\right)}{2 \alpha \sigma_{1}^{2} \sigma_{2}^{2}+e L\left(\sigma_{1}^{2}+\sigma_{2}^{2}\right)}
$$

\section{A.3.2 Minimum Wage Model}

\section{Oligopsony}

$$
\begin{aligned}
& \max _{n_{i 1}}, n_{i 2} n_{i 1}\left(\bar{y}_{1}-w_{1}\right)+ n_{i 2}\left(\bar{y}_{2}-w_{2}\right)-\alpha\left(n_{i 1}^{2} \sigma_{1}^{2}+n_{i 2}^{2} \sigma_{2}^{2}\right) . \\
& \text { s.t. }:\left\{\begin{array}{c}
w=\max \left(\underline{w} ; w_{1}^{\star}\right) \\
w_{2}=\max \left(\underline{w} ; w_{2}^{\star}\right) \\
w_{j}=e\left(\sum_{k=1}^{K} n_{k j}\right)+f
\end{array}\right\}
\end{aligned}
$$

First, we derive solutions without the first two constraints. Then, we verify whether the derived values fit with the constraints.

$$
\begin{array}{lll}
\max _{n_{i 1}, n_{2}} n_{i 1}\left[\bar{y}_{1}-f-e\left(n_{i 1}+\sum_{k \neq j} n_{k 1}\right)\right] & +n_{i 2}\left[\bar{y}_{2}-f-e\left(n_{i 2}+\sum_{k \neq j} n_{k 2}\right)\right] \\
& -\alpha\left(n_{i 1}^{2} \sigma_{1}^{2}+n_{i 2}^{2} \sigma_{2}^{2}\right) \\
\Leftrightarrow \frac{\partial-}{\partial n_{i 1}}=0 & \Leftrightarrow \frac{\partial-}{\partial n_{i 2}}=0 \\
\Leftrightarrow \bar{y}_{1}-2 e n_{i 1}-f-2 \alpha n_{i 1} \sigma_{1}^{2} & \Leftrightarrow \bar{y}_{2}-2 e n_{i 2}-f-2 \alpha n_{i 2} \sigma_{2}^{2} \\
-e \sum_{k \neq j} n_{k 1}=0 & -e \sum_{k \neq j} n_{k 2}=0 \\
\Leftrightarrow n_{i 1}^{M W}=\frac{\bar{y}_{1}-f}{e(K+1)+2 \alpha \sigma_{1}^{2}} & \Leftrightarrow n_{i 2}^{M W}=\frac{\bar{y}_{2}-f}{e(K+1)+2 \alpha \sigma_{2}^{2}} \\
\Rightarrow W_{1}^{M W}=e K \frac{\bar{y}_{1}-f}{e(K+1)+2 \alpha \sigma_{1}^{2}}+f>\bar{W} & \Rightarrow w_{2}^{M W}=e K \frac{\bar{y}_{2}-f}{e(K+1)+2 \alpha \sigma_{2}^{2}}+f<\bar{W}
\end{array}
$$

But $w_{2}^{M W}$ must be $\geq \bar{w}$. Therefore, $w_{2}^{M W}=\bar{w}$ and $n_{i 2}^{M W}=\frac{\bar{w}-f}{e K}$.

\section{Monopsony}

$$
\begin{gathered}
\max _{n_{1}, n_{2}} n_{1}\left(\bar{y}_{1}-w_{1}\right)+n_{2}\left(\bar{y}_{2}-w_{2}\right)-\alpha\left(n_{1}^{2} \sigma_{1}^{2}+n_{2}^{2} \sigma_{2}^{2}\right) . \\
\text { s.t. }:\left\{\begin{array}{l}
w_{1}=\max \left(\underline{w} ; w_{1}^{\star}\right) \\
w_{2}=\max \left(\underline{w} ; w_{2}^{\star}\right) \\
w_{j}=e n_{j}+f
\end{array}\right\}
\end{gathered}
$$


First, we derive solutions without the first two constraints. Then, we verify whether the derived values fit with the constraints.

$$
\begin{aligned}
& \max _{n_{1}, n_{2}} n_{1}\left(\bar{y}_{1}-f-e n_{1}\right)+n_{2}\left(\bar{y}_{2}-f-e n_{2}\right)-\alpha\left(n_{1}^{2} \sigma_{1}^{2}+n_{21}^{2} \sigma_{2}^{2}\right) \\
& \Leftrightarrow \frac{\partial-}{\partial n_{1}}=0 \quad \Leftrightarrow \frac{\partial-}{\partial n_{2}}=0 \\
& \Leftrightarrow \bar{y}_{1}-2 e n_{1}-f-2 \alpha n_{1} \sigma_{1}^{2}=0 \quad \Leftrightarrow \bar{y}_{2}-2 e n_{2}-f-2 \alpha n_{2} \sigma_{2}^{2}=0 \\
& \Leftrightarrow n_{1}^{M W}=\frac{\bar{y}_{1}-f}{2\left(e+\alpha \sigma_{1}^{2}\right)} \quad \Leftrightarrow n_{2}^{M W}=\frac{\bar{y}_{2}-f}{2\left(e+\alpha \sigma_{2}^{2}\right)} \\
& \Rightarrow W_{1}^{M W}=e \frac{\bar{y}_{1}-f}{2\left(e+\alpha \sigma_{1}^{2}\right)}+f>\bar{W} \quad \Rightarrow w_{2}^{M W}=e \frac{\bar{y}_{2}-f}{2\left(e+\alpha \sigma_{2}^{2}\right)}+f<\bar{W}
\end{aligned}
$$

But $w_{2}^{M W}$ must be $\geq \bar{w}$. Therefore, $w_{2}^{M W}=\bar{w}$ and $n_{2}^{M W}=\frac{\bar{w}-f}{e}$.

\section{Competition}

$$
\begin{gathered}
\max _{n_{i 1}, n_{i 2}} n_{i 1}\left(\bar{y}_{1}-w_{1}\right)+n_{i 2}\left(\bar{y}_{2}-w_{2}\right)-\alpha\left(n_{i 1}^{2} \sigma_{1}^{2}+n_{i 2}^{2} \sigma_{2}^{2}\right) . \\
\text { s.t. }:\left\{\begin{array}{c}
w=\max \left(\underline{w} ; w_{1}^{\star}\right) \\
w_{2}=\max \left(\underline{w} ; w_{2}^{\star}\right)
\end{array}\right\}
\end{gathered}
$$

First, we derive solutions without the two constraints. Then, we verify whether the derived values fit with the constraints.

$$
\begin{aligned}
& \max _{n_{i 1}, n_{i 2}} n_{i 1}\left(\bar{y}_{1}-w_{1}\right)+n_{i 2}\left(\bar{y}_{2}-w_{2}\right)-\alpha\left(n_{i 1}^{2} \sigma_{1}^{2}+n_{i 2}^{2} \sigma_{2}^{2}\right) \\
& \Leftrightarrow \frac{\partial-}{\partial n_{i 1}}=0 \quad \Leftrightarrow \frac{\partial-}{\partial n_{i 2}}=0 \\
& \Leftrightarrow \bar{y}_{1}-w_{1}-2 \alpha n_{1} \sigma_{1}^{2}=0 \quad \Leftrightarrow \bar{y}_{2}-w_{2}-2 \alpha n_{2} \sigma_{2}^{2}=0 \\
& \Leftrightarrow n_{i 1}=\frac{\bar{y}_{1}-w_{1}}{2 \alpha \sigma_{1}^{2}} \quad \Leftrightarrow n_{i 2}=\frac{\bar{y}_{2}-w_{2}}{2 \alpha \sigma_{2}^{2}}
\end{aligned}
$$

In the labour market with symmetrical firms, we have:

$$
\begin{array}{ll}
\left\{\begin{array}{c}
n_{i 1}=\frac{\bar{y}_{1}-w_{1}}{2 \alpha \sigma_{1}^{2}} \\
w_{i 1}=e L n_{i 1}+f
\end{array}\right\} & \left\{\begin{array}{c}
n_{i 2}=\frac{\bar{y}_{2}-w_{2}}{2 \alpha \sigma_{2}^{2}} \\
w_{i 2}=e L n_{i 2}+f
\end{array}\right\} \\
\Leftrightarrow n_{i 1}^{c}=\frac{\bar{y}_{1}-f}{e L+2 \alpha \sigma_{1}^{2}} & \Leftrightarrow n_{i 2}^{c}=\frac{\bar{y}_{2}-f}{e L+2 \alpha \sigma_{2}^{2}} \\
\Rightarrow w_{1}^{c}=e L \frac{\bar{y}_{1}-f}{e L+2 \alpha \sigma_{1}^{2}}+f & \Rightarrow w_{i 2}^{c}=e L \frac{\bar{y}_{2}-f}{e L+2 \alpha \sigma_{2}^{2}}+f
\end{array}
$$

But $w_{2}^{M W}$ must be $\geq \bar{w}$. Therefore, $w_{2}^{M W}=\bar{w}$ and $n_{2}^{M W}=\frac{\bar{y}_{2}-\bar{w}}{2 \alpha \sigma_{2}^{2}}$. 


\section{A.3.3 Quota Model}

\section{Oligopsony}

$$
\begin{aligned}
& \max _{n_{i}} n_{i} \bar{y}_{1}+n_{i} \bar{y}_{2}-2 n_{i}\left(f+e n_{i}+e \sum_{k \neq i} n_{k}\right)-\alpha n_{i}^{2}\left(\sigma_{1}^{2}+\sigma_{2}^{2}\right) \\
& \Leftrightarrow \frac{\partial-}{\partial n_{i}}=0 \\
& \Leftrightarrow \bar{y}_{1}+\bar{y}_{2}-2\left(f+2 e n_{i}+e \sum_{k \neq j} n_{k}\right)-2 \alpha n_{i}\left(\sigma_{1}^{2}+\sigma_{2}^{2}\right)=0 \\
& \Leftrightarrow n^{\prime}=\frac{\frac{\bar{y}_{1}+\bar{y}_{2}}{2}-f}{e(K+1)+\alpha\left(\sigma_{1}^{2}+\sigma_{2}^{2}\right)} \\
& \Rightarrow w^{\prime}=e K \frac{\frac{\bar{y}_{1}+\bar{y}_{2}}{2}-f}{e(K+1)+\alpha\left(\sigma_{1}^{2}+\sigma_{2}^{2}\right)}+f
\end{aligned}
$$

\section{Monopsony}

$$
\begin{aligned}
& \max _{n} n \bar{y}_{1}+n \bar{y}_{2}-2 n(f+e n)-\alpha n^{2}\left(\sigma_{1}^{2}+\sigma_{2}^{2}\right) \\
& \Leftrightarrow \frac{\partial-}{\partial n}=0 \\
& \Leftrightarrow \bar{y}_{1}+\bar{y}_{2}-2(f+2 e n)-2 \alpha n\left(\sigma_{1}^{2}+\sigma_{2}^{2}\right)=0 \\
& \Leftrightarrow n^{\prime}=\frac{\frac{\bar{y}_{1}+\bar{y}_{2}}{2}-f}{2 e+\alpha\left(\sigma_{1}^{2}+\sigma_{2}^{2}\right)} \\
& \Rightarrow w^{\prime}=e \frac{\frac{\bar{y}_{1}+\bar{y}_{2}}{2}-f}{2 e+\alpha\left(\sigma_{1}^{2}+\sigma_{2}^{2}\right)}+f
\end{aligned}
$$

\section{Competition}

$$
\begin{aligned}
& \max _{n_{i}} n_{i}\left(\bar{y}_{1}+\bar{y}_{2}-w_{i 1}-w_{i 2}\right)-\alpha n_{i}^{2}\left(\sigma_{1}^{2}+\sigma_{2}^{2}\right) \\
& \Leftrightarrow \frac{\partial-}{\partial n_{i}}=0 \\
& \Leftrightarrow \bar{y}_{1}+\bar{y}_{2}-w_{i 1}-w_{i 2}-2 \alpha n\left(\sigma_{1}^{2}+\sigma_{2}^{2}\right)=0
\end{aligned}
$$

In the labour market with symmetrical firms, we have:

$$
\begin{aligned}
& \left\{\begin{array}{c}
\bar{y}_{1}+\bar{y}_{2}-w_{i 1}-w_{i 2}-2 \alpha n\left(\sigma_{1}^{2}+\sigma_{2}^{2}\right)=0 \\
w_{i 1}=e L n_{i 1}+f \\
w_{i 2}=e L n_{i 2}+f
\end{array}\right\} \\
& n^{\prime \prime}=\frac{\frac{\bar{y}_{1}+\bar{y}_{2}}{2}-f}{e L+\alpha\left(\sigma_{1}^{2}+\sigma_{2}^{2}\right)} \\
& W^{\prime \prime}=e L \frac{\frac{\bar{y}_{1}+\bar{y}_{2}}{2}-f}{e L+\alpha\left(\sigma_{1}^{2}+\sigma_{2}^{2}\right)}+f
\end{aligned}
$$




\section{A.3.4 Disadvantaged Subsidy Model}

\section{Oligopsony}

$$
\begin{array}{lc}
\max _{n_{1}, n_{2}} n_{i 1}\left[\bar{y}_{1}-f-e\left(n_{i 1}+\sum_{k \neq j} n_{k 1}\right)\right]+n_{i 2}\left[\bar{y}_{2}-f-e\left(n_{i 2}+\sum_{k \neq j} n_{k 2}\right)+\tau\right] \\
-\alpha\left(n_{i 1}^{2} \sigma_{1}^{2}+n_{i 2}^{2} \sigma_{2}^{2}\right)
\end{array}
$$

Value of $\tau^{\star}$

We want $n_{1}^{\tau}=n_{2}^{\tau}$.

$$
\begin{aligned}
& \Leftrightarrow \frac{\bar{y}_{1}-f}{e(K+1)+2 \alpha \sigma_{1}^{2}}=\frac{\bar{y}_{2}-f+\tau}{e(K+1)+2 \alpha \sigma_{2}^{2}} \\
& \Leftrightarrow \tau=\frac{\bar{y}_{1}-f}{e(K+1)+2 \alpha \sigma_{1}^{2}}\left(e(K+1)+2 \alpha \sigma_{2}^{2}\right)-\bar{y}_{2}+f \\
& \Leftrightarrow \tau=\frac{\bar{y}_{1}-f}{e(K+1)+2 \alpha \sigma_{1}^{2}}\left(e(K+1)+2 \alpha \sigma_{2}^{2}\right)-\frac{\bar{y}_{2}-f}{e(K+1)+2 \alpha \sigma_{1}^{2}}\left(e(K+1)+2 \alpha \sigma_{1}^{2}\right) \\
& \Leftrightarrow \tau^{*}=\frac{e(K+1)\left(\bar{y}_{1}-\bar{y}_{2}\right)+2 \alpha\left(\sigma_{2}^{2} \bar{y}_{1}-\sigma_{1}^{2} \bar{y}_{2}\right)-2 \alpha f\left(\sigma_{2}^{2}-\sigma_{1}^{2}\right)}{e(K+1)+2 \alpha \sigma_{1}^{2}}
\end{aligned}
$$

Then, it is easy to verify that $\tau^{\star}$ is also compatible with equality of wages.

\section{Monopsony}

$$
\begin{array}{ll}
\quad \max _{n_{1}, n_{2}} n_{1}\left(\bar{y}_{1}-f-e n_{1}\right)+n_{2}\left(\bar{y}_{2}-f-e n_{2}+\tau\right)-\alpha\left(n_{1}^{2} \sigma_{1}^{2}+n_{21}^{2} \sigma_{2}^{2}\right) \\
\Leftrightarrow \frac{\partial-}{\partial n_{1}}=0 & \Leftrightarrow \frac{\partial-}{\partial n_{2}}=0 \\
\Leftrightarrow \bar{y}_{1}-2 e n_{1}-f-2 \alpha n_{1} \sigma_{1}^{2}=0 & \Leftrightarrow \bar{y}_{2}-2 e n_{2}-f-2 \alpha n_{2} \sigma_{2}^{2}+\tau=0 \\
\Leftrightarrow n_{1}^{\tau}=\frac{\bar{y}_{1}-f}{2\left(e+\alpha \sigma_{1}^{2}\right)} & \Leftrightarrow n_{2}^{\tau}=\frac{\bar{y}_{2}-f+\tau}{2\left(e+\alpha \sigma_{2}^{2}\right)} \\
\Rightarrow w_{1}^{\tau}=e \frac{\bar{y}_{1}-f}{2\left(e+\alpha \sigma_{1}^{2}\right)}+f & \Rightarrow w_{2}^{\tau}=e \frac{\bar{y}_{2}-f+\tau}{2\left(e+\alpha \sigma_{2}^{2}\right)}+f
\end{array}
$$

Value of $\tau^{\star}$

We want $n_{1}^{\tau}=n_{2}^{\tau}$. 


$$
\begin{aligned}
& \Leftrightarrow \frac{\bar{y}_{1}-f}{2\left(e+\alpha \sigma_{1}^{2}\right)}=\frac{\bar{y}_{2}-f+\tau}{2\left(e+\alpha \sigma_{2}^{2}\right)} \\
& \Leftrightarrow \tau=\frac{\bar{y}_{1}-f}{e+\alpha \sigma_{1}^{2}}\left(e+\alpha \sigma_{2}^{2}\right)-\bar{y}_{2}+f \\
& \Leftrightarrow \tau=\frac{\bar{y}_{1}-f}{e+\alpha \sigma_{1}^{2}}\left(e+\alpha \sigma_{2}^{2}\right)-\frac{\bar{y}_{2}-f}{e+\alpha \sigma_{1}^{2}}\left(e+\alpha \sigma_{1}^{2}\right) \\
& \Leftrightarrow \tau^{\star}=\frac{e\left(\bar{y}_{1}-\bar{y}_{2}\right)+\alpha\left(\sigma_{2}^{2} \bar{y}_{1}-\sigma_{1}^{2} \bar{y}_{2}\right)-\alpha f\left(\sigma_{2}^{2}-\sigma_{1}^{2}\right)}{e+\alpha \sigma_{1}^{2}}
\end{aligned}
$$

Then, it is easy to verify that $\tau^{\star}$ is also compatible with equality of wages.

\section{Competition}

$$
\begin{array}{ll}
\max _{n_{i 1}, n_{i 2}} n_{i 1}\left(\bar{y}_{1}-w_{1}\right)+n_{i 2}\left(\bar{y}_{2}-w_{2}+\tau\right)-\alpha\left(n_{i 1}^{2} \sigma_{1}^{2}+n_{i 2}^{2} \sigma_{2}^{2}\right) \\
\Leftrightarrow \frac{\partial-}{\partial n_{i 1}}=0 & \Leftrightarrow \frac{\partial-}{\partial n_{i 2}}=0 \\
\Leftrightarrow \bar{y}_{1}-w_{1}-2 \alpha n_{1} \sigma_{1}^{2}=0 & \Leftrightarrow \bar{y}_{2}-w_{2}+\tau-2 \alpha n_{2} \sigma_{2}^{2}=0 \\
\Leftrightarrow n_{i 1}=\frac{\bar{y}_{1}-w_{1}}{2 \alpha \sigma_{1}^{2}} & \Leftrightarrow n_{i 2}=\frac{\bar{y}_{2}-w_{2}}{2 \alpha \sigma_{2}^{2}}
\end{array}
$$

In the labour market with symmetrical firms, we have:

$$
\begin{array}{ll}
\left\{\begin{array}{c}
n_{i 1}=\frac{\bar{y}_{1}-w_{1}}{2 \alpha \sigma_{1}^{2}} \\
w_{i 1}=e L n_{i 1}+f
\end{array}\right\} & \left\{\begin{array}{l}
n_{i 2}=\frac{\bar{y}_{2}-w_{2}+\tau}{2 \alpha \sigma_{2}^{2}} \\
w_{i 2}=e L n_{i 2}+f
\end{array}\right\} \\
\Leftrightarrow n_{i 1}^{c}=\frac{\bar{y}_{1}-f}{e L+2 \alpha \sigma_{1}^{2}} & \Leftrightarrow n_{i 2}^{c}=\frac{\bar{y}_{2}-f+\tau}{e L+2 \alpha \sigma_{2}^{2}} \\
\Rightarrow w_{1}^{c}=e L \frac{\bar{y}_{1}-f}{e L+2 \alpha \sigma_{1}^{2}}+f & \Rightarrow w_{i 2}^{c}=e L \frac{\bar{y}_{2}-f+\tau}{e L+2 \alpha \sigma_{2}^{2}}+f
\end{array}
$$

Value of $\tau^{\star}$

We want $n_{1}^{\tau}=n_{2}^{\tau}$.

$$
\begin{aligned}
& \Leftrightarrow \frac{\bar{y}_{1}-f}{e L+2 \alpha \sigma_{1}^{2}}=\frac{\bar{y}_{2}-f+\tau}{e L+2 \alpha \sigma_{2}^{2}} \\
& \Leftrightarrow \tau=\frac{\bar{y}_{1}-f}{e L+2 \alpha \sigma_{1}^{2}}\left(e L+2 \alpha \sigma_{2}^{2}\right)-\bar{y}_{2}+f \\
& \Leftrightarrow \tau=\frac{\bar{y}_{1}-f}{e L+2 \alpha \sigma_{1}^{2}}\left(e L+2 \alpha \sigma_{2}^{2}\right)-\frac{\bar{y}_{2}-f}{e L+2 \alpha \sigma_{1}^{2}}\left(e L+2 \alpha \sigma_{1}^{2}\right) \\
& \Leftrightarrow \tau^{*}=\frac{e L\left(\bar{y}_{1}-\bar{y}_{2}\right)+2 \alpha\left(\sigma_{2}^{2} \bar{y}_{1}-\sigma_{1}^{2} \bar{y}_{2}\right)-2 \alpha f\left(\sigma_{2}^{2}-\sigma_{1}^{2}\right)}{e L+2 \alpha \sigma_{1}^{2}}
\end{aligned}
$$

\section{References}

Aigner, D., and C. Cain. 1977. "Statistical Theories of Discrimination in Labor Markets." Industrial and Labor Relations Review 30 (2):175-87. 
Arrow, K. 1972. "The Theory of Discrimination." In Discrimination in Labor Markets, edited by

O. Ashenfelter, and A. Rees. Princeton, NJ: Princeton University Press. 3-33.

Arrow, K. 1998. "What Has Economics to Say About Racial Discrimination." Journal of Economic Perspectives 12 (2):91-100.

Becker, G. 1957. The Economics of Discrimination. Chicago: University of Chicago Press.

Bhaskar, V., A. Manning, and T. To. 2002. "Oligopsony and Monopsonistic Competition in Labor Markets." Journal of Economic Perspectives 16 (2):155-74.

Bjerk, D. 2008. "Glass Ceilings or Sticky Floors? Statistical Discrimination in a Dynamic Model of Hiring and Promotion." Economic Journal 118 (530):961-82.

Cahuc, P., and G. Laroque. 2014. "Optimal Taxation and Monopsonistic Labor Market: Does Monopsony Justify the Minimum Wage?" Journal of Public Economic Theory 16 (2):259-73.

Coate, S., and G. Loury. 1993. "Will Affirmative Action Eliminate Negative Stereotypes?." American Economic Review 83 (5):1220-40.

Cornell, B., and I. Welch. 1996. "Culture, Information and Screening Discrimination." Journal of Political Economy 104 (3):542-71.

Dickinson, D., and R. Oaxaca. 2009. "Statistical Discrimination in Labor Markets: An Experimental Analysis." Southern Economic Journal 76 (1):16-31.

Goldberg, P. 1996. "Dealer Price Discrimination in New Car Purchases: Evidence From the Consumer Expenditure Survey." Journal of Political Economy 104 (3):622-34.

Heckman, J. 1998. “Detecting Discrimination.” Journal of Economic Perspectives 12 (2):101-16.

Holzer, H., and D. Neumark. 1999. "Are Affirmative Action Hires Less Qualified? Evidence From Employer-Employee Data on New Hires.” Journal of Labor Economics 17 (3):534-69.

Holzer, H., and D. Neumark. 2000a. "Assessing Affirmative Action." Journal of Economic Literature 38 (3):483-568.

Holzer, H., and D. Neumark. 2000b. "What Does Affirmative Action Do?" Industrial and Labor Relations Review 53 (2):240-71.

Klumpp, T., and X. Su. 2013. "Second-Order Statistical Discrimination." Journal of Public Economics 97 (1):108-16.

Lang, K. 1986. “A Language Theory of Discrimination." Quarterly Journal of Economics 101 (2):363-81.

Leonard, J. 1984. "The Impact of Affirmative Action on Employment." Journal of Labor Economics $2(4): 439-63$.

Leonard, J. 1990. "The Impact of Affirmative Action Regulation and Equal Employment Opportunity Law on Black Employment." Journal of Economic Perspectives 4 (4):47-64.

Lundberg, S. 1991. "The Enforcement of Equal Opportunity Laws Under Imperfect Information: Affirmative Action and Alternatives." Quarterly Journal of Economics 106 (1):309-26.

Lundberg, S., and R. Startz. 1983. "Private Discrimination and Social Intervention in Competitive Labor Market." American Economic Review 73 (3):340-7.

Morgan, J., and F. Várdy. 2009. "Diversity in the Workplace." American Economic Review 99 (1):472-85.

Moro, A., and P. Norman. 2004. “A General Equilibrium Model of Statistical Discrimination.” Journal of Economic Theory 114 (1):1-30.

Neumark, D. 2012. "Detecting Discrimination in Audit and Correspondence Studies." Journal of Human Resources 47 (4):1128-57.

Neumark, D., and W. Stock. 2006. "The Labour Market Effects of Sex and Race Discrimination Laws.” Economic Inquiry 44 (3):385-419. 
Phelps, E. 1972. "The Statistical Theory of Racism and Sexism." American Economic Review 62 (4):659-61.

Smith, J., and F. Welch. 1984. "Affirmative Action and Labor Markets." Journal of Labor Economics 2 (2):269-302.

Welch, F. 1976. “Employment Quotas for Minorities.” Journal of Political Economy 84 (4):105-39.

Wozniak, A. 2015. "Discrimination and the Effects of Drug Testing on Black Employment." Review of Economics and Statistics 97 (3):548-66. 